\title{
Characterization of Chromatin Subfractions Enriched in RNA from Lactating Mammary Gland of the Rat
}

\author{
Masaaki Hirose, Keiko AnABUKI, Masatoshi MaKi, ${ }^{*}$ \\ Kiyozo Hasegawa and Hideo ChiBA* \\ Department of Food Science and Nutrition, Nara Women's University, \\ Nara, Nara 630, Japan \\ *Department of Food Science and Technology, Kyoto University, \\ Kyoto, Kyoto 606, Japan \\ Received April 14, 1980
}

\begin{abstract}
Mammary gland chromatin from lactating rats was fractionated according to the $\mathrm{Mg}^{2+}$. solubility method after mild digestion with DNase II. The chromatin properties were compared between the $\mathrm{Mg}^{2+}$-soluble $\left(\mathrm{S}_{2}\right)$ and the $\mathrm{Mg}^{2+}$-insoluble $\left(\mathrm{P}_{2}\right)$ fractions. The weight ratio of RNA to DNA was much greater in the $S_{2}$ fraction than in the $P_{2}$ fraction $\left(S_{2}, 0.92 ; P_{2}, 0.03\right)$. The DNA repeat length of the nucleosome was very similar between the two fractions $\left(S_{2}, 193 \pm 7 ; P_{2}, 196 \pm 8\right.$ nucleotide pairs). A significant difference was seen in electrophoretic pattern of $\mathrm{Hl}$ histone between the two fractions in the acid-urea gel system. Nonhistone proteins with molecular weights higher than about 40,000 dalton were found to be enriched in the $S_{2}$ fraction.
\end{abstract}

Milk protein synthesis in the mammary gland is controlled by the multiple interactions of peptide and steroid hormones. The regulation of RNA synthesis, including specific mRNA coding for casein, has been shown to be involved in the induction of the milk proteins. $\left.{ }^{1} \sim 5\right)$ Recent studies have revealed that the accumulation of casein mRNA is induced by prolactin and that this induction is stimulated by glucocorticoid, but inhibited by progestin..$^{6 \sim 11)}$

There is extensive evidence to support that steroid hormones act on their target tissues by the formation of high affinity complexes with cytoplasmic receptors which translocate to the nuclei and bind acceptor sites of chromatin. In previous reports, we have shown that changes in chromatin structure play, at least in part, an important role in the regulation of RNA synthesis in the rat mammary gland, and that a steroid receptor which commonly hinds progestin and glucocorticoid might be involved in this regulation. ${ }^{12 \sim 14)}$

As prerequisite experiments for detailed investigation concerning the interaction between chromatin and the receptor, we have undertaken experiments to fractionate mammary gland chromatin from lactating rats into the active and inactive chromatin. Several reports using DNase 1 , which has been shown to digest transcriptionally active chromatin regions preferentially, have shown that the high mobility group proteins and acetylated $\mathrm{H} 4$ histone are involved in the structure of these chromatin regions. ${ }^{15 \sim 18)}$ DNase I is, however, known to digest DNA in the nucleosome cores as well as in linkers. ${ }^{19}$ ) Therefore, it could not be achieved by using DNase I to fractionate the active and inactive chromatin with the fundamental nucleosome structure.

In the present paper, mammary gland chromatin from lactating rats has been fractionated into transcriptionally active and inactive regions with the method using DNase II. $^{20 \sim 23)}$ The structure of these chromatin subfractions has been compared to investigate the correlations between transcriptional activity and the structure of chromatin.

\section{MATERIALS AND METHODS}

Reagents. Micrococcal nuclease (grade VI) and DNase 
II (DN-II-HP) and phenylmethylsulfonyl fluoride were purchased from Sigma. Restriction endonuclease Hinc II digests of $\phi \mathrm{X}-174 \mathrm{RF}$ DNA was obtained from New England Biolabs. Proteinase $K$ was purchased from Boehringer.

Fractionation of chromatin. Female Wistar rats of 5 to 7th day of lactation were decapitated and the removed mammary glands were frozen on dry ice and stored at $-80^{\circ} \mathrm{C}$. Nuclei were prepared as described earlier. ${ }^{13)}$ Two milliliters of nuclear solution $(1.0 \mathrm{mg} / \mathrm{ml}$ DNA in $50 \mathrm{~mm}$ Tris- $\mathrm{HCl}$, pH 7.5 containing $2.0 \mathrm{mM} \mathrm{MgCl}_{2}, 0.5 \mathrm{~mm}$ phenylmethylsulfonyl fiuoride and $50 \%$ glycerol) were centrifuged at $10,000 \times g$ for $10 \mathrm{~min}$, and the pellet was gently lysed in $2.0 \mathrm{ml}$ of $0.2 \mathrm{~mm}$ EDTA, $\mathrm{pH} 7.0$ with a potter homogenizer. To the sample, $2.0 \mathrm{ml}$ of Buffer $A$ ( $50 \mathrm{~mm}$ acetate- $\mathrm{NaOH}$, pH $6.7,1.0 \mathrm{~mm}$ phenylmethylsulfonyl fuoride) were added, then the suspension was homogenized in the same way. The sample was centrifuged at $10,000 \times g$ for $15 \mathrm{~min}$, and the precipitate was homogenized in $3.0 \mathrm{ml}$ of Buffer $\mathrm{B}$ ( $25 \mathrm{~mm}$ acetate- $\mathrm{NaOH}$, $\mathrm{pH} 6.7$ containing $0.5 \mathrm{~mm}$ phenylmethylsulfonyl fluoride).

DNase II digestion and fractionation of chromatin were performed essentially as described by Gottesfeld et al ${ }^{20)}$ After DNase II digestion under the conditions described in the legends of Figures, the sample was separated into the first supernatant and pellet $\left(\mathrm{P}_{1}\right)$ by centrifugation at $34,000 \times g$ for $15 \mathrm{~min}$. The supernatant was further factionated by the addition of $\mathrm{MgCl}_{2}$. The precipitate was removed by centrifugation $(35,000 \times g$ for $15 \mathrm{~min})$. The second pellet is termed $\mathrm{P}_{2}$ and the supernatant of $\mathrm{Mg}^{2+}$. soluble chromatin fraction is termed $\mathrm{S}_{2}$. The fractionated chromatin samples were analyzed for DNA, RNA, histone and nonhistone proteins as described by Spelsberg et al. ${ }^{24)}$

Gel electrophoresis of $D N A$. The samples from $\mathrm{P}_{1}, \mathrm{P}_{2}$ and $\mathrm{S}_{2}$ fractions were incubated with $0.05 \mathrm{mg} / \mathrm{ml}$ of proteinase $\mathrm{K}$ in $2.0 \mathrm{mM}$ EDTA and $0.2 \%$ sodium dodecyl sulfate at $37^{\circ} \mathrm{C}$ for $2 \mathrm{hr}$. DNA was isolated by phenol extraction as described earlier. ${ }^{13}$ Electrophoresis was carried out in $2.5 \%$ polyacrylamide $-0.5 \%$ agarose gels. The gels were stained with $0.002 \%$ ethidium bromide for $20 \mathrm{~min}$ and the DNA bands were photographed through a red filter on illumination with ultraviolet light. Sizes of DNA were determined by using the restriction endonulcease Hinc II digest of $\phi \mathrm{X}-174 \mathrm{RF}$ DNA.

Analyses of histones. Histones were prepared by acid extraction from the chromatin fractions and subsequent precipitation in ethanol as described by Bonner et al. ${ }^{25)}$ Electrophoresis was carried out in the buffer system by Panyim et $a^{26}{ }^{261}$ or by Laemmli. ${ }^{27}$

In the former system, gels contained $15 \%$ acrylamide$0.1 \%$ methylenebisacrylamide, and were run at $115 \mathrm{~V}$ for $21 \mathrm{hr}$ at $4 . \mathrm{C}$. Gels were stained with $0.25 \%$ Coomassie blue in $20 \%$ methanol $-7 \%$ acetic acid overnight, and destained in $20 \%$ methanol-7\% acetic acid.
In the latter system, the concentration of acrylamide and methylenebisacrylamide was the same as described by Laemmli. ${ }^{27)}$ Electrophoresis was carried out with a current of $30 \mathrm{~mA}$ per slab gel until bromophenol blue maker reached the bottom of the gel (about $4 \mathrm{hr}$ ). Gels were fixed in $50 \%$ ethanol $10 \%$ acetic acid for $1 \mathrm{hr}$ and stained in $0.1 \%$ Coomassie blue-50\% acetic acid-10\% methanol overnight, and destained in $7 \%$ acetic acid.

The high mobility group proteins. The high mobility group (HMG) proteins were isolated from the $P_{1}, P_{2}$ and $\mathrm{S}_{2}$ fractions according to the procedure of Walker et al. ${ }^{28 \text { ) }}$ Electrophoresis was carried out in the buffer system of Johns. ${ }^{29)}$ Gels were run at $200 \mathrm{~V}$ for $4.5 \mathrm{hr}$ at $4^{\circ} \mathrm{C}$, then stained and destained as described for the electrophoresis of histones. Gels were stained with $0.25 \%$ Coomassie blue in $20 \%$ methanol- $7 \%$ acetic acid overnight, and destained in $20 \%$ methanol- $7 \%$ acetic acid.

Nonhistone proteins. Nonhistone chromosomal proteins were prepared from the $P_{2}$ and $S_{2}$ fractions according to the method by Wilson and Spelsberg. ${ }^{30)}$ Electrophoresis was performed in the buffer system of Laemmli. ${ }^{27}$ Gels were run at $30 \mathrm{~mA}$ for about $4 \mathrm{hr}$ at $4^{\circ} \mathrm{C}$, then they were stained and destained as described for the electrophoresis of histones.

Densitometric tracings were carried out with a Shimadzu densitometer CS-900.

\section{RESULTS}

\section{Composition of chromatin fractions}

Time course of nuclease digestion of mammary gland chromatin was examined by fractionating the samples after different times of incubation with DNase II. Data in Fig. 1 show that the amounts of DNA in the $\mathrm{Mg}^{2+}$. soluble $\left(\mathrm{S}_{2}\right)$ and insoluble $\left(\mathrm{P}_{2}\right)$ fractions increased gradually until $15 \mathrm{~min}$, then they reached plateaus. The amounts of DNA in the $\mathrm{P}_{1}$ fraction decreased during the incubation period.

The composition of DNA, RNA, histone and nonhistone proteins in the fractionated chromatin was analyzed after 15 min-digestion by DNase II. As shown in Table I, histone to DNA ratio was not greatly variable among the $P_{1}, \quad P_{2}$ and $S_{2}$ fractions $(0.91 \sim 1.21)$. In contrast, the quantities of RNA was markedly enriched in the $S_{2}$ fraction. The RNA to DNA ratio was 0.92 in the $S_{2}$ fraction, but those in the $P_{1}$ and $P_{2}$ fractions were only 0.1 and 0.03 , respectively. These data support the idea that 


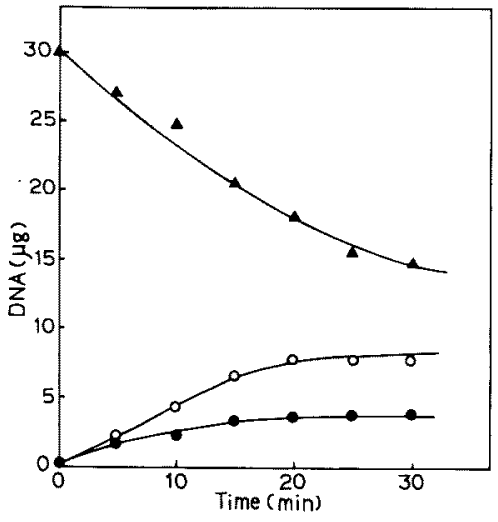

FIG. 1. The Time Course of DNase II Digestion.

Nuclear solution $(0.1 \mathrm{ml}$ in Buffer B) was incubated with 8.3 units of DNase II at $25^{\circ} \mathrm{C}$. At various times, the reaction was terminated by the addition of 0.1 volume of $50 \mathrm{~mm}$ Tris- $\mathrm{HCl}$ buffer, $\mathrm{pH} 8.1$, and cooling on ice. The sample was fractionated as described in the text, and the amounts of DNA in the $P_{1}(\Delta), P_{2}(O)$ and $S_{2}(\boldsymbol{O})$ fraction were determined by the diphenylamine method. ${ }^{34)}$

Table I. Chemical Composition of the Subfractions from Rat Mammary Gland Chromatin

\begin{tabular}{lccc}
\hline \multirow{2}{*}{ Fraction } & \multicolumn{3}{c}{$\mathrm{mg} / \mathrm{mg}$ of DNA } \\
\cline { 2 - 4 } & Histone & $\begin{array}{c}\text { Nonhistone } \\
\text { proteins }\end{array}$ & RNA \\
\hline Whole chromatin & 1.25 & 0.97 & 0.17 \\
$\mathbf{P}_{1}$ fraction & 1.21 & 1.32 & 0.10 \\
$\mathbf{P}_{2}$ fraction & 0.91 & 0.37 & 0.03 \\
$\mathbf{S}_{2}$ fraction & 1.00 & 0.42 & 0.92 \\
\hline
\end{tabular}

the $S_{2}$ fraction is enriched in the actively transcribing genes. The slight enrichment of nonhistone proteins was seen in the $P_{1}$ fraction, but not in the $P_{2}$ and $S_{2}$ fractions.

\section{Gel electrophoresis of histones}

Histones isolated from the $\mathrm{P}_{2}$ and $\mathrm{S}_{2}$ fractions were analyzed by gel electrophoresis. Figure 2(A) shows the densitometric tracings of the gels which were run in the acid-urea system. The patterns of $\mathrm{H} 2 \mathrm{~A}, \mathrm{H} 2 \mathrm{~B}, \mathrm{H} 3$ and $\mathrm{H} 4$ histones were essentially unvariable between the two different fractions. However, the electrophoretic patterns of $\mathrm{H} 1$ histone from

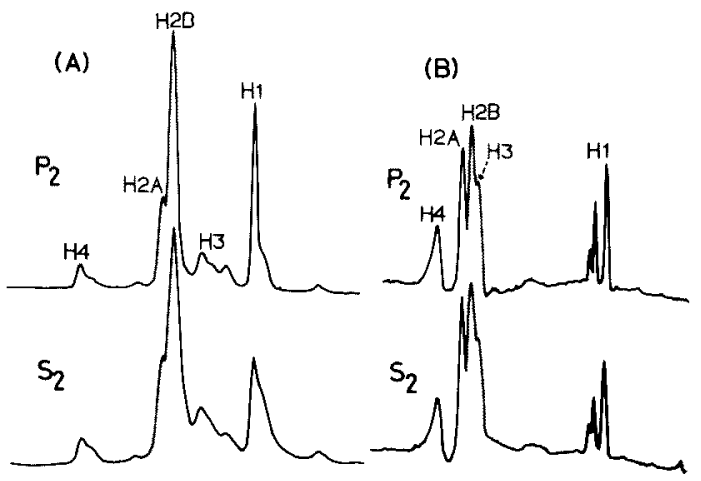

FIG. 2. Electrophoretic Patterns of Histones.

One milliliter of nuclear solution in Buffer $\mathrm{B}$ was digested with 110 units of DNase II at $25^{\circ} \mathrm{C}$ for $15 \mathrm{~min}$. The reaction was terminated and the samples were fractionated as described in the legend to Fig. 1. Histones from the $S_{2}$ and $P_{2}$ fraction were run on the acid-urea gel system (A) and the gel system containing sodium dodecyl sulfate (B).

the $S_{2}$ fraction was different from that of the $P_{2}$ fraction. Under these electrophoretic conditions, there appeared in the $\mathrm{P}_{2}$ fraction at least two $\mathrm{Hl}$ components, a main peak and a shoulder with lower mobility. The ratio of a slowly migrating $\mathrm{H} 1$ component to the main peak appeared greater in the $S_{2}$ fraction than in the $\mathrm{P}_{2}$ fraction. It has been shown that $\mathrm{Hl}$ histone is more susceptible to proteases than the other histones. But the difference in the electrophoretic patterns does not appear to be due to the differential proteolysis, because the ratio of the area of $\mathrm{H} 1$ peak to that of $\mathrm{H} 2 \mathrm{~A}$ plus $\mathrm{H} 2 \mathrm{~B}$ histones was similar between the two different fractions $\left(P_{2}, 0.40 ; S_{2}, 0.43\right)$. When gel electrophoresis was carried out in the system containing sodium dodecyl sulfate, the occurrence of three different components was observed with regard to $\mathrm{Hl}$ histone. No significant difference of protein bands was seen between the $\mathrm{P}_{2}$ and $\mathrm{S}_{2}$ fractions (Fig. 2(B)).

\section{Nonhistone proteins}

As shown in earlier reports, ${ }^{12,13)}$ the quantities and gel electrophoretic patterns of nonhistone proteins were greatly variable during the mammary gland development in 


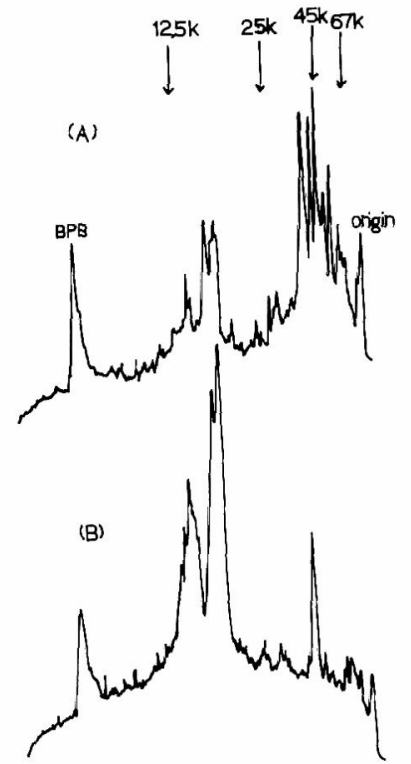

Fig. 3. Nonhistone Proteins of the Two Different Fractions.

DNase II digestion and the fractionation were carried out in the same way as described in the legend to Fig. 2. Nonhistone proteins from the $S_{2}$ (A) and the $P_{2}$ (B) fractions were electrophoresed on the gel system containing sodium dodecyl sulfate.

which the control of transcriptional activities is involved. The electrophoretic patterns of nonhistone proteins in the gel system containing sodium dodecyl sulfate were compared between the active $S_{2}$ fraction and the inactive $\mathrm{P}_{2}$ fraction. In the $\mathrm{S}_{2}$ fraction, seven major peaks were seen in the molecular weight range of more than 40,000 (Fig. 3). These peaks were not seen in the $\mathrm{P}_{2}$ fraction except one peak with a molecular weight of about 40,000 . In contrast, proteins with lower molecular weight than about 15,000 were enriched in the $P_{2}$ fraction. These protein bands were observed in lower extent in the $S_{2}$ fraction.

\section{The high mobility group proteins}

The functions of a group of nonhistone chromosomal proteins called the high mobility group (HMG) proteins have been investigated by examining the fractions from chromatin regions susceptible to DNase I which has been shown to preferentially degrade the DNA of

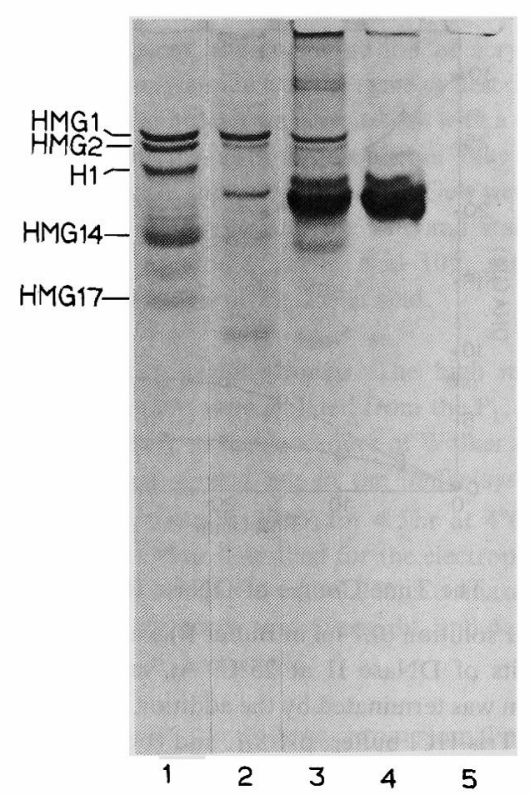

Fig. 4. Acid Gel Electrophoresis of the High Mobility Group Proteins.

DNase II digestion and the fractionation were carried out in the same way as in the legend to Fig. 2. The HMG proteins were isolated from the three different fractions and were dissolved in $50 \mu 1$ of $\mathrm{H}_{2} \mathrm{O}$. Fifteen microliter of the samples were subjected to the acid-gel electrophoresis. Slot 1, the HMG proteins from calf thymus: slot 2 , the proteins from whole mammary gland nuclei; slot 3 , from the $P_{1}$ fraction; slot 4 , from the $P_{2}$ fraction; slot 5 , from the $S_{2}$ fraction.

actively transcribed genes. Regarding to these investigations, there is a controversy as to whether the HMG proteins are associated with transcriptionally active genes in chromatin. ${ }^{15,31)}$ To see if the HMG proteins are associated with active genes in the mammary gland chromatin, these proteins from the three different fractions $\left(\mathrm{P}_{1}, \mathrm{P}_{2}\right.$ and $\mathrm{S}_{2}$ fractions) were subjected to the analyses by acid-gel electrophoresis. As shown in Fig. 4, the peaks of HMG1 and HMG2 as well as unidentified several peaks were seen in the $P_{1}$ fraction. No significant band of the $\mathrm{HMG}$ proteins was observed in the fractions of $\mathrm{P}_{2}$ and $\mathrm{S}_{2}$.

\section{$D N A$ repeat length of nucleosome}

The sizes of DNA were compared among the three different fractions to see if the 


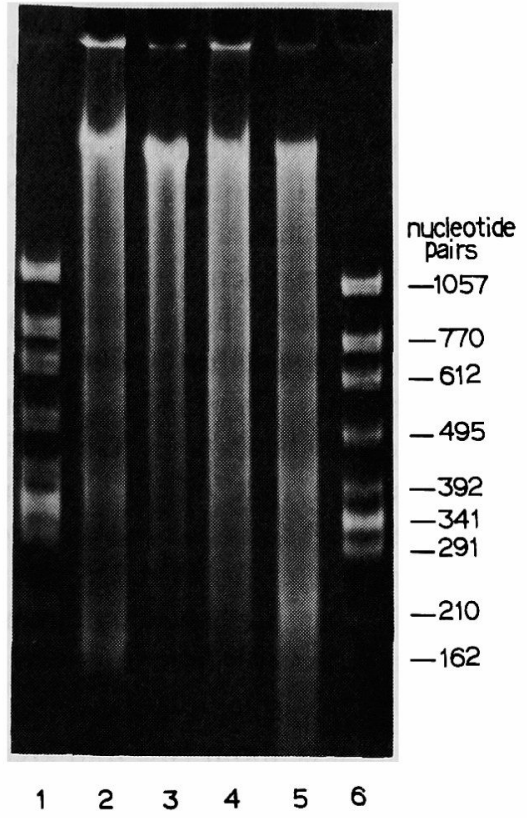

FIG. 5. Polyacrylamide-agarose Gel Electrophoresis of Nuclease Digests from Mammary Gland Nuclei.

After nuclear solution $(3.0 \mathrm{ml})$ was incubated with 300 units of DNase II at $25^{\circ} \mathrm{C}$ for $7 \mathrm{~min}$, the sample was fractionated into three fractions by the same way as in Fig. 2. DNA was isolated from these fractions as described in the text. The slots 3, 4 and 5 represent the patterns of DNA fragments from the $P_{1}, P_{2}$ and $S_{2}$ fraction, respectively. The restriction fragments from Hinc II digests of $\phi \mathrm{X}-174$ RF DNA were electrophoresed in the slot 1 and 6 . In the slot 2, micrococcal nuclease digests of whole nuclei prepared as described earlier ${ }^{13)}$ were electrophoresed.

variation in nucleosome structure is correlated with the active and the inactive chromatin structure. Figure 5 shows that DNA fragments from the $P_{2}$ and $S_{2}$ fractions migrated on polyacrylamide-agarose gels as multiples of a repeat length. With respect to the $\mathrm{P}_{1}$ fraction, electrophoretic pattern appeared smear except that a single band with higher molecular weight was seen. To determine the DNA sizes, the logarithms of restriction fragment length were plotted against distance of migration. As shown in Fig. 6, the sizes of the DNA fragments were very similar between the $\mathrm{P}_{2}$ and $S_{2}$ fractions. The DNA repeat length was calculated to be $193 \pm 7$ and $196 \pm 8$ for the $S_{2}$

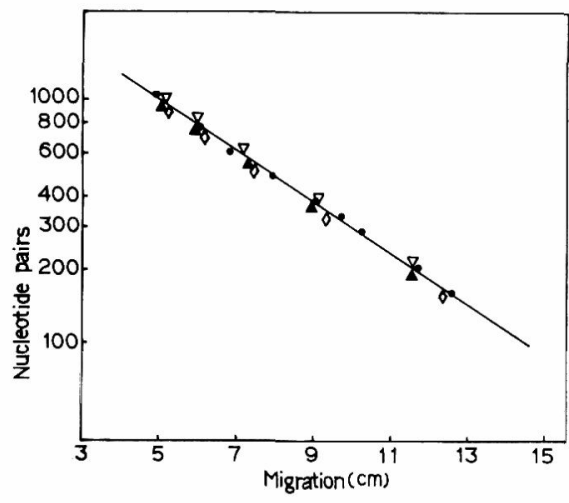

FIG. 6. Determination of the Sizes of DNA Fragments.

The distance of migration of Hinc II fragments of $\phi X$ 174 RF DNA (Fig. 5) was plotted against logarithms of the number of nucleotide pairs (O). With this plot, the sizes of DNA bands from the $P_{2}(\Delta)$ and $S_{2}(\nabla)$ fractions were determined. The symbol, $\diamond$, represents the DNA bands from micrococcal nuclease digests of whole nuclei.

and $\mathrm{P}_{2}$ fraction, respectively. These data were consistent with the DNA repeat length of micrococcal nuclease digests $(195 \pm 3$ nucleotide pairs).

\section{DISCUSSION}

Knowledge of the fundamental structure of chromatin has been accumulated in terms of nucleosome. ${ }^{19)}$ However, the question as to the correlation between the biological activity and the structure of chromatin appears still open. Weintraub and Groudine first demonstrated that pancreatic DNase I preferentially degrade the chromatin DNA of actively transcribed genes. ${ }^{32)}$ Data from several laboratories have shown that chromatin regions containing hyperacetylated histones are preferentially digested by this nuclease, ${ }^{16 ~ 18)}$ suggesting that acetylated histone is implicated in the structure of active chromatin. DNase I, however, has been shown to degrade the DNA involved in the core structure of the nucleosome as well as the linker DNA. ${ }^{19)}$ Therefore, it does not appear to be achieved by using DNase I digestion that chromatin structure including 
the nucleosome structure is compared between the active and the inactive chromatin. Gottesfeld et al. have devised a procedure to fractionate active and inactive chromatin by using spleen DNase II. ${ }^{20)}$ This method includes separating a soluble chromatin fraction (active) in the solution containing $\mathrm{Mg}^{2+}$ from an insoluble fraction (inactive).

To study the correlation between structure and transcriptional activity, chromatin from the mammary gland of the lactating rat was fractionated into active and inactive fraction after mild digestion with DNase II. In the active fraction the RNA content was significantly enriched (Table I). Therefore, the active fraction corresponds to subfractions of actively transcribed genes in mammary gland chromatin. There was no significant difference between the active and inactive fraction regarding to the sizes of DNA repeat length of nucleosome (active, 193 \pm 7 ; inactive, 196 \pm 8 nucleotide pairs, Fig. 5). These data coincided with the DNA repeat length which was obtained by micrococcal nuclease digestion of whole nuclei $(195 \pm 3)$. Therefore, the length of DNA in the repeat unit is probably the same for the active and inactive chromatin fractions of rat mammary gland. This observation is consistent with the data by Gottesfeld and Butler which have shown that the DNA repeat length is the same for these chromatin fractions from rat liver. ${ }^{211}$

Although the quantities of nonhistone proteins per DNA were not significantly different between the $S_{2}$ and $P_{2}$ fractions, the electrophoretic patterns were quite different between these two fractions. In the $\mathrm{S}_{2}$ fraction, protein bands with higher molecular weight than about 40,000 dalton were enriched, while higher peaks with lower molecular weight were seen in the $\mathrm{P}_{2}$ fraction.

Electrophoretic patterns of $\mathrm{H} 1$ histone in acid-urea system were significantly different between the $S_{2}$ and $P_{2}$ fractions. The difference were not seen in the gel system containing sodium dodecyl sulfate in which proteins with sequence heterogeneity could be separated. Therefore, the difference in the acid-urea gels may be due to the variability in posttranslational modifications such as phosphorylation.

It has been investigated by using DNase I whether the HMG proteins are associated with the DNA of actively transcribed genes. Concerning this problem, there is a controversy. Levy et al. ${ }^{15)}$ have shown that the HMG proteins are specifically liberated from trout testis chromatin by mild digestion with DNase I, whereas the data by Goodwin and Johns have shown that this is not true for thymus nuclei. ${ }^{31)}$ As shown in our previous report, the amount of the HMG proteins per DNA was greater in lactating mammary glands than in regression tissues. ${ }^{13)}$ The mammary gland chromatin template activity for in vitro transcription is about two-fold greater in lactation than in regression stages. ${ }^{12)}$ The data in mammary gland chromatin appeared to support the former argument. In the present study, however, no enrichment in the HMG proteins was seen in the active $S_{2}$ fraction (Fig. 4). Recent data by Goodwin et al. have shown that protein degradation occurs during the isolation procedure of the HMG proteins from calf thymus chromatin. ${ }^{33)}$ To evaluate more clearly whether the HMG proteins are associated with the active regions of mammary gland chromatin, it may be necessary to examine under the conditions including the presence of more potent protease inhibitors than phenylmethylsulfonyl fluoride employed in the present report.

\section{REFERENCES}

1) M. R. Banerjee and D. N. Banerjee, Exptl. Cell Res., 64, 307 (1971).

2) P. Chomczyński, W. Sokól-Misiak and D. Kleczkowska, FEBS Lett., 76, 191 (1977).

3) L. M. Houdebine and P. Gaye, Molecular Cellular Endocrinol., 3, 37 (1975).

4) J. M. Rosen, S. L. C. Woo and J. P. Comstock, Biochemistry, 14, 2895 (1975).

5) H. L. Nakhasi and P. K. Quasba, J. Biol. Chem., 254, 6016 (1979).

6) L. M. Houdebine, Eur. J. Biochem., 68, 219 (1976).

7) E. Devinoy and L. M. Houdebine, Eur. J. Biochem., 75, 411 (1977). 
8) P. M. Terry, K. R. Banerjee and R. M. Lui, Proc. Natl. Acad. Sci. USA, 74, 2441 (1977).

9) J. M. Rosen, D. L. O'Neal, J. E. McHugh and J. P. Comstock, Biochemistry, 17, 290 (1978).

10) R. J. Matusik and J. M. Rosen, J. Biol. Chem., 253, 2343 (1978).

11) E. Devinoy, L. M. Houdebine and C. Delouis, Biochim. Biophys. Acta, 517, 360 (1978).

12) M. Hirose, M. Maki and H. Chiba, J. Biochem., 83, 1205 (1978).

13) M. Hirose, M. Maki, K. Anabuki, K. Hasegawa and H. Chiba, Agric. Biol. Chem., 43, 2143 (1979).

14) M. Hirose, M. Maki and H. Chiba, Biochim. Biophys. Acta, 629, 168 (1980).

15) W. B. Levy, N. C. Wong and G. H. Dixon, Proc. Natl. Acad. Sci. USA, 74, 2810 (1977).

16) D. A. Nelson, W. M. Perry and R. Chalkley, Biochem. Biophys. Res. Commun., 82, 356 (1978).

17) D. A. Nelson, M. Perry, L. Sealy and R. Chalkley, Biochem. Biophys. Res. Commun., 82, 1346 (1978).

18) C. K. Shewmaker, B. N. Cohen and T. E. Wagner, Biochem. Biophys. Res. Commun., 84, 342 (1978).

19) G. Felsenfeld, Nature, 271, 115 (1978).

20) J. M. Gottesfeld, W. T. Garrard, G. Bagi, R. F. Wilson and J. Bonner, Proc. Natl. Acad. Sci. USA, 71, 2193 (1974).

21) J. M. Gottesfeld and P. J. G. Butler, Nucleic Acid Res., 4, 3155 (1977).

22) R. B. Wallace, S. K. Dube and J. Bonner, Science,
198, 1166 (1977).

23) J. M. Gottesfeld and G. A. Partington, Cell, 12, 953 (1977).

24) T. C. Spelsberg, A. W. Steggles and B. W. O'Malley, J. Biol. Chem., 246, 4188 (1971).

25) J. Bonner, G. R. Chalkley, M. Dahmus, D. Fambrough, F. Fujimura, R. C. Huang, J. Huberman, R. Jensen, K. Marushige, $H$. Chelenbusch, B. Olivera and J. Widholm, "Methods in Enzymology," Vol. XII (part B), ed. by L. Grossman and K. Moldave, Academic Press Inc., New York, N.Y., 1968, p. 3.

26) S. Panyim and R. Chalkley, Arch. Biochem. Biophys, 130, 337 (1969).

27) U. K. Laemmli, Nature, 227, 680 (1970).

28) J. M. Walker, G. H. Goodwin and E. W. Johns, FEBS Lett., 90, 327 (1978).

29) E. W. Johns, J. Chromato., 42, 152 (1969).

30) E. W. Wilson and T. C. Spelsberg, "Methods in Enzymology," Vol. XL (part E), ed. by B. W. O’Malley, Academic Press Inc., New York, N.Y., 1975, p. 171.

31) G. H. Goodwin and E. W. Johns, Biochim. Biophys. Acta, 519, 279 (1978).

32) H. Weintraub and M. Groudine, Science, 193, 848 (1976).

33) G. H. Goodwin, J. M. Walker and E. W. Johns, Biochim. Biophys. Acta, 519, 233 (1978).

34) K. Burton, Biochem. J., 62, 315 (1956). 